$$
\begin{gathered}
\text { UNIVERSITY OF CALIFORNIA } \\
\text { COLLEGE OF AGRICULTURE } \\
\text { AGRICULTURAL EXPERIMENT STATION } \\
\text { BERKELEY, CALIFORNIA }
\end{gathered}
$$

\title{
SPRAY-FUMIGATION TREATMENT FOR RESISTANT RED SCALE ON LEMONS
}

H. J. QUAYLE and WALTER EBELING

\section{BULLETIN 583}

AUGUST, 1934 



\title{
SPRAY-FUMIGATION TREATMENT FOR RESISTANT RED SCALE ON LEMONS ${ }^{1,2}$
}

\author{
H. J. QUAYLE ${ }^{3}$ AND WALTER EBELING ${ }^{4}$
}

\section{INTRODUCTION}

Fumigation with hydrocyanic acid was a satisfactory method of controlling the red scale, Aonidiella aurantii (1[ask.), on citrus trees in California up to approximately 1912. At about that time growers and fumigators began to observe that satisfactory results were not obtained, even with an increased dosage, in one or two restricted localities. The area where the red scale is not satisfactorily controlled by fumigation has since greatly increased. However, fumigation is still the most satisfactory single treatment even for the resistant red scale on lemons, and it is entirely satisfactory for the nonresistant red scale which occurs over the greater portion of the citrus areas.

Quayle (1916, 1920, 1922) and Woglum (1925), by taking lemons infested with the red scale from different localities and fumigating these in the same chamber or enclosure, came to the conclusion that there was a difference in tolerance or resistance of the red scale to hydrocyanic acid in different localities in California. Twenty years of field experience, as well as further experimental evidence, has confirmed that conclusion. Evidence that the black scale, Saissetia oleae (Bern.), has also become resistant to fumigation has been shown by Quayle (1922), Woglum (1925), and Gray and Kirkpatrick (1929). Very much later than the time when fumigation was first failing to control the red and black scales, the citricola scale, Coccus pseudomagnoliarum (Kuw.), began (about 1925) to exhibit greater tolerance to hydrocyanic acid. The fact that greater tolerance or resistance has been shown to exist in two other citrus scales in certain areas lends additional support to the belief that the same phenomenon exists in the red scale.

The failure of fumigation to control these scales effectively led to the use of oil sprays. It has proved, however, to be difficult to kill the red scale with any spray, at least at a concentration (Smith, 1932; and

1 Received for publication May 31, 1934.

2 Paper No. 307, University of California Graduate School of Tropical Agriculture and Citrus Experiment Station, Riverside, California.

3 Professor of Entomology and Entomologist in the Experiment Station.

4 Junior Entomologist in the Citrus Experiment Station. 
Ebeling, 1932) that is not more or less harmiful to the tree in some districts. The failure of the sprays is especially marked where the scales occur on the woody bark. In order to determine the part the spray plays in the spray-fumigation treatment, tests with different sprays were conducted and the results of most of them in use up to 1932 are given in the following pages.

The origin of the oil-spray-fumigation treatment dates back to 1925, when W. M. Mertz, a grower and manager of citrus properties, happened to fumigate a block of trees that had been sprayed a week or two previously, with the result that the red scale was rather satisfactorily controlled. This of course was to be expected, from the fact that two treatments should give better results than a single treatment. But the results from the spray-fumigation treatment seemed to be superior to two fumigations or to two sprayings. This was shown later to be the case (Quayle, 1927; and Ebeling, 1931) and it is accounted for by a number of different factors. With fumigation, the best results are secured on the old wood and leaves and the poorest on the fruit, while with oil sprays the best results occur on the fruit and leaves and the poorest on the old wood. The scales on the outside fruits near the tent are the ones that are especially likely to survive the fumigation, while the same scales are the ones most likely to be hit and killed by the spray. The spray tends to loosen some of the scales from the surface to which they are attached, without killing them. These partially lifted or loosened scales, however, may succumb more readily to the fumigation than those scales that are still well sealed to the surface. For these reasons spraying and fumigating are complementary treatments.

The primary object of the experiments herein reported was an accurate comparison of results obtained by the spray-fumigation treatment with those obtained by spraying alone and by two fumigations.

Other questions on which data are given include the advantage or disadvantage of applying the spray first; the most satisfactory interval between treatments; the best kind of spray to use; the relation of spray coverage to fumigation results; the most satisfactory interval for two fumigations; the effect of the spray-fumigation treatment on the tree and fruit, and its relation to the general program of pest control on lemon trees. 


\section{1-32 SRAY-FUMIGATION EXPERIMENTS}

The data presented are based chiefly on experiments carried on in thirteen lemon groves in Los Angeles and Orange counties. There were six different plots of from 25 to 30 trees in each of the groves. Six different spray treatments were applied (in August and September) and each was followed by fumigation of two different dosages at intervals of from four days to eight months.

TABLE 1

Distillation Range and Sulfonation of the Two Oils USED IN TANK-MIXTURE SPRAYS

\begin{tabular}{|c|c|c|}
\hline Degrees Fahrenheit & $\begin{array}{c}\text { Grade } 4 \\
\text { Sulfonation } 93 \text { per cent }\end{array}$ & $\begin{array}{c}\text { Grade } 5 \\
\text { Sulfonation } 95 \text { per cent }\end{array}$ \\
\hline $550 \ldots$ & $\begin{array}{c}\text { per cent distilled } \\
0\end{array}$ & $\begin{array}{c}\text { per cent distilled } \\
0\end{array}$ \\
\hline $575 \ldots$ & 3 & 1 \\
\hline $600 \ldots$ & 13 & 4 \\
\hline $625 \ldots$. & 36 & 19 \\
\hline $650 \ldots$. & 56 & 43 \\
\hline $675 \ldots$ & 73 & 59 \\
\hline $700 \ldots \ldots$ & 84 & 77 \\
\hline $725 \ldots \ldots$. & $90+$ & 86 \\
\hline $750 \ldots \ldots \ldots \ldots \ldots$ & $\ldots$. & $90+$ \\
\hline
\end{tabular}

The groves selected were the most heavily infested with red scale that could be found in the different districts. The spraying was done by commercial operators working under our direction; the fumigation work was done by the Citrus Experiment Station. Nothing more than good commercial work is claimed for the operations.

The percentage of insects alive was separately determined on the fruit and on the branches prior to the spraying in each of the groves.

The average percentage alive in all of the groves on both fruit and branches at that time is indicated at the bottom of the $A$ charts (figs. 1 to 6 ) on which the spraying results are shown.

Inspection of the spray-charts will show that there was a higher percentage of scales killed on the fruit than on the branches. The variability shown in the results is more or less comparable to that found in commercial spraying over a similar number of groves. While a heavy infestation of scale occurred in all of the groves, some were more severely infested than others, and the degree of infestation is one factor that influences the results. The results of the spraying were determined six weeks after the applications by examining scales on both fruit and branches. The average of all groves for each particular spray is given near the bottom of the $A$ charts in figures 1 to 6 , and in figure 7. 
The two oils constituting the sprays used are designated as Grade 4 (medium) and Grade 5 (heavy), as given by Smith (1932). The distillation range and sulfonation are shown in table 1.

The commercial emulsions employed were made of oil of about the same general specifications as given above, and all were used at 2 per cent. Four ounces of blood albumin spreader to 100 gallons of diluted spray were used in the tank-mixture sprays and the percentage of oil varied, as indicated in the $A$ charts (figs. 1 to 6 ) from $1 \frac{1}{2}$ to $2 \frac{1}{2}$ per cent.

On the $B$ charts of figures 1 to 6 are given the results of the fumigation following each of the sprays in all of the groves at intervals of from four days to eight months, and at dosages of $22 \mathrm{cc}$ and 24 cc. ${ }^{5}$ The results of the fumigation were determined ten days after treatment by examining scale insects on both fruit and branches. It will be noted that the percentage scale on the $B$ charts of figures 1 to 6 is different from that on the $A$ charts-that is, an interval on the $B$ charts represents a much smaller percentage than the same-sized interval on the $A$ charts. This change of scale is necessitated by the fact that most of the results of the spray-fumigation treatment fall within a fraction of 1 per cent, whereas those of spray alone run to as high as 60 per cent.

A summary of the oil-spray results in all of the groves is given in figure 7. It will be noted that a higher percentage of scales survived in all cases on the branches than on the fruit. The percentage of survival on the branches ranged from 8.17 to 27.2 per cent, while the percentage of survival on the fruit ranged from 4.0 to 7.4 per cent.

The value of fumigation alone in comparison with spraying was not made in this study because of the extensive past experience with fumigation, both in an experimental way and in commercial practice. However, a general idea may be gained of the value of fumigation alone by reference to the results of the first fumigations in figures 8 and 9.

Of the intervals between spraying and fumigation chosen in this investigation, the 10 and 15-day intervals show the best results. Postponing the fumigation until winter has a number of advantages, from the grower's standpoint, and a considerable amount of winter fumigation has been carried on during the past few years. We recommend either that fumigation follow the spraying at an interval of approximately 10 or 15 days, or that it be postponed until January, February, or March.

5 The dosages as indicated represent dosages of HCN as used on lemons in commercial citrus fumigation in California, $20 \mathrm{ec}$ of $\mathrm{HCN}$ corresponding to about 1 ounce of sodium cyanide (51-52 per cent cyanogen). This is approximately the amount used under tents covering average-sized trees. The dosage used on lemons is usually higher than that used on oranges. 

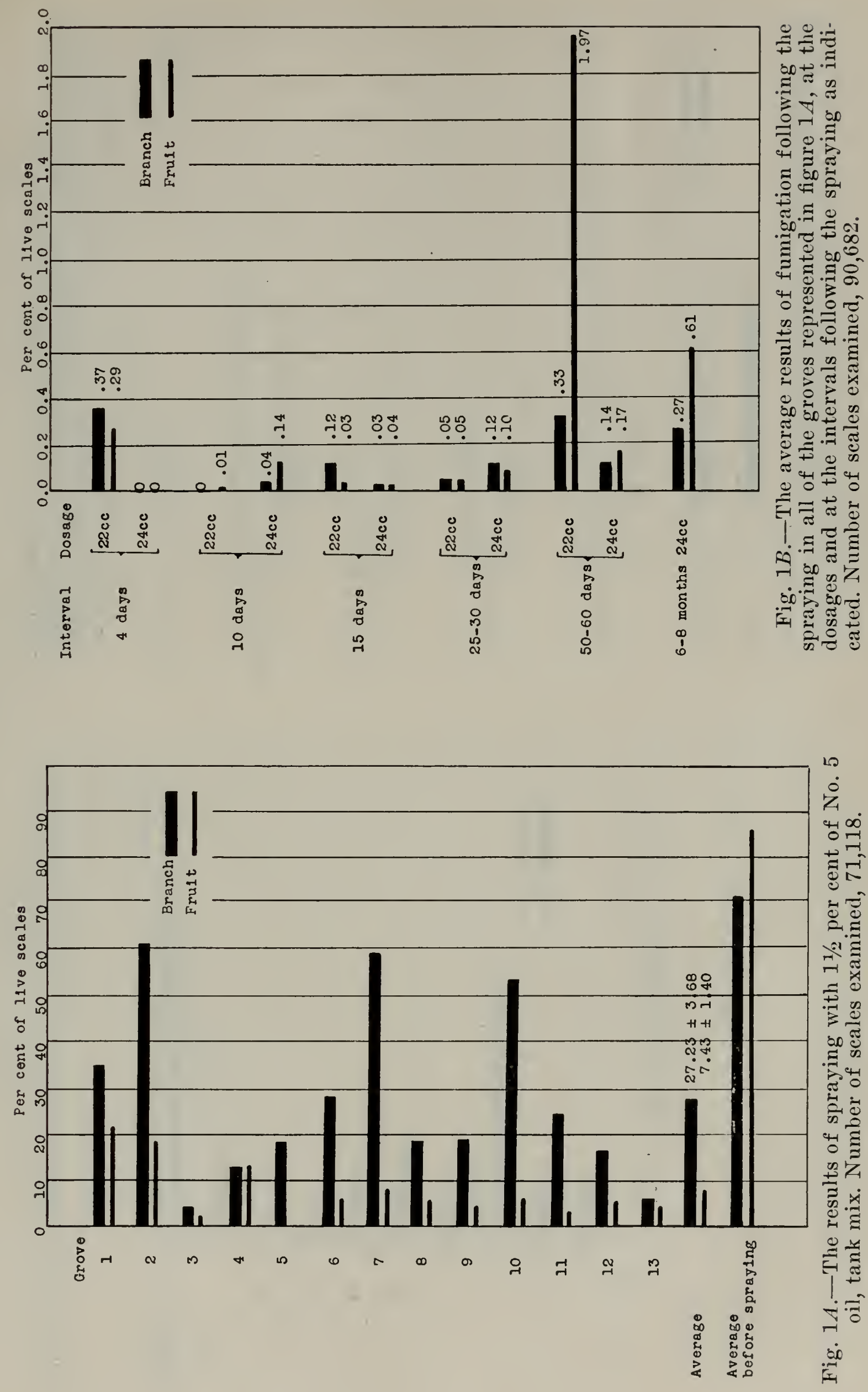

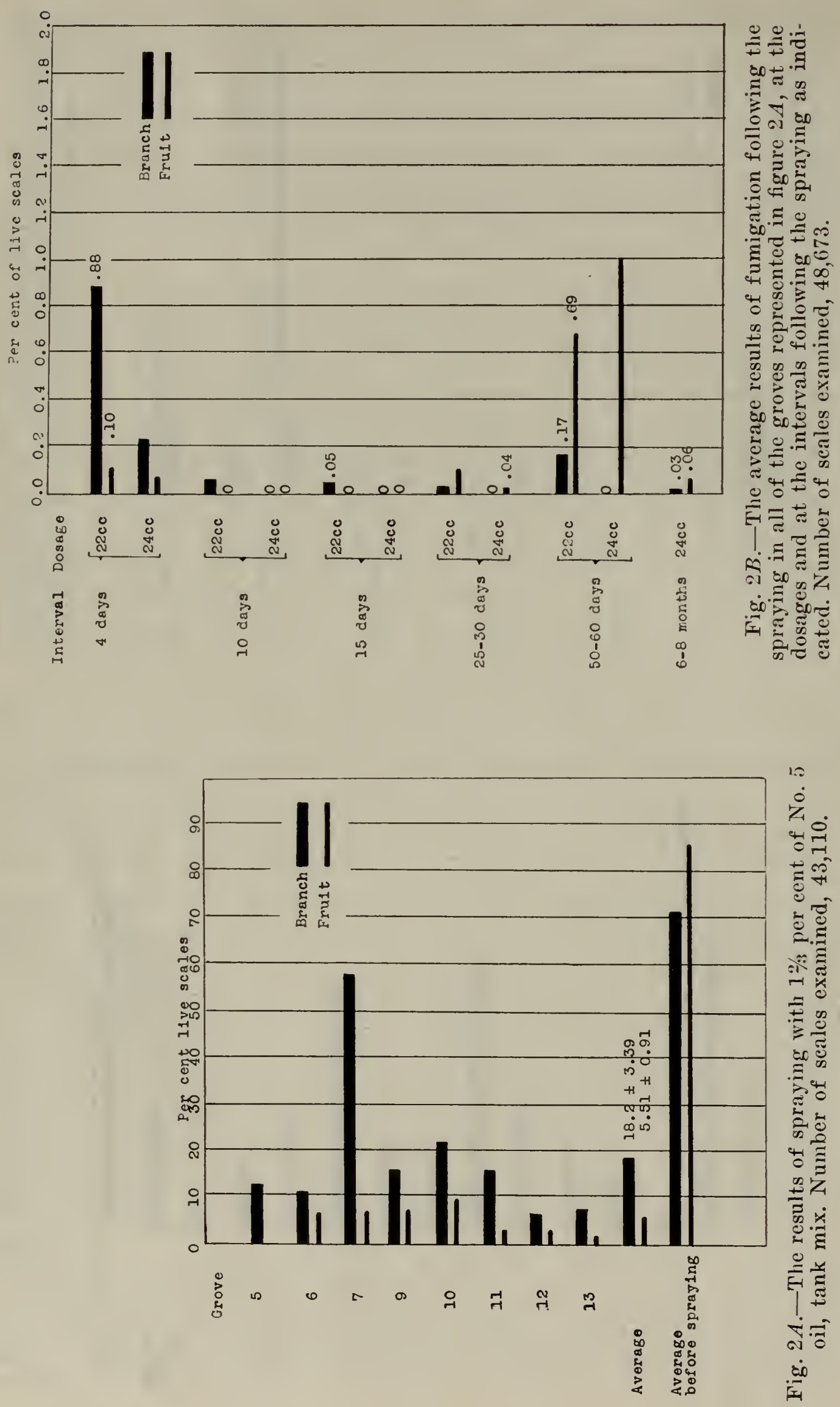

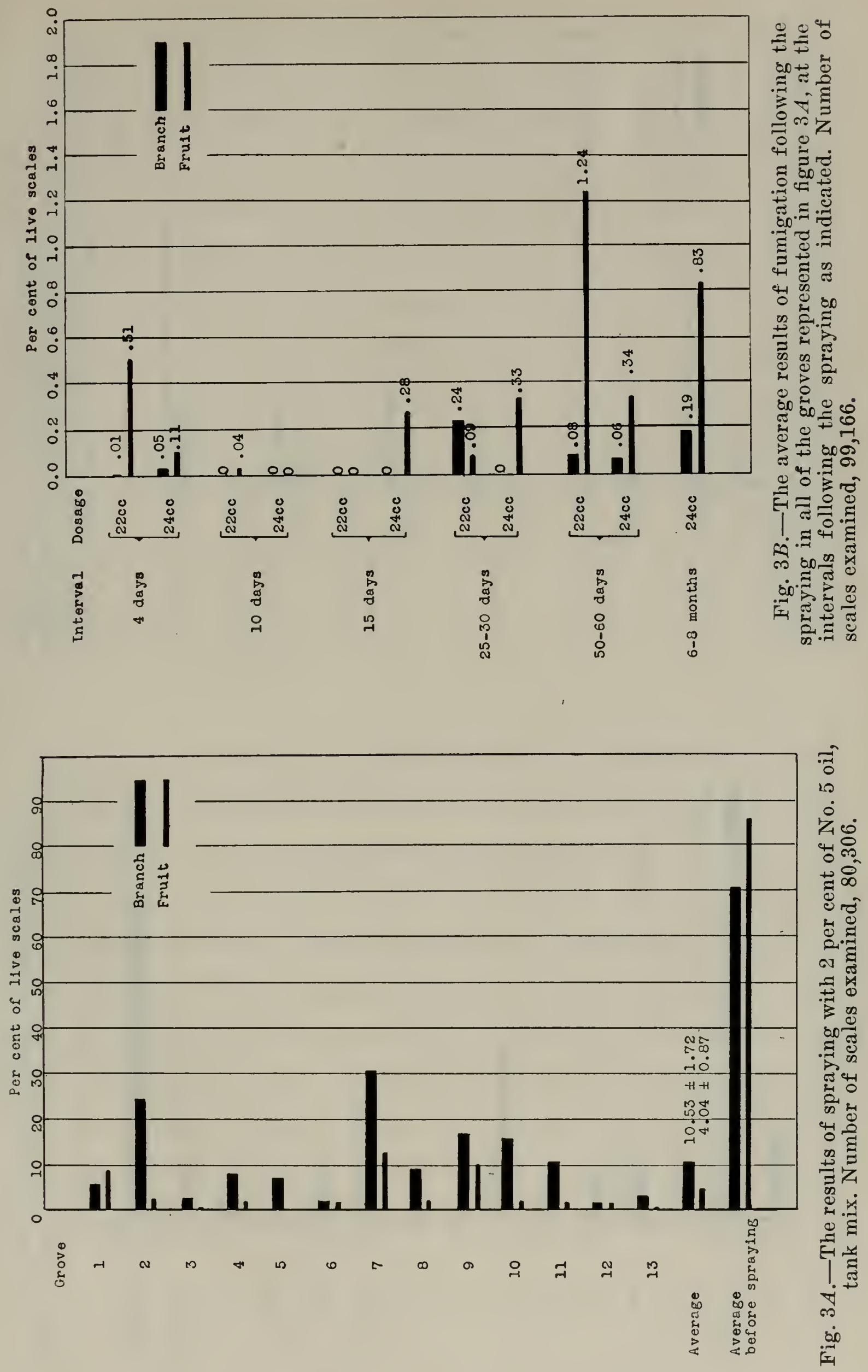

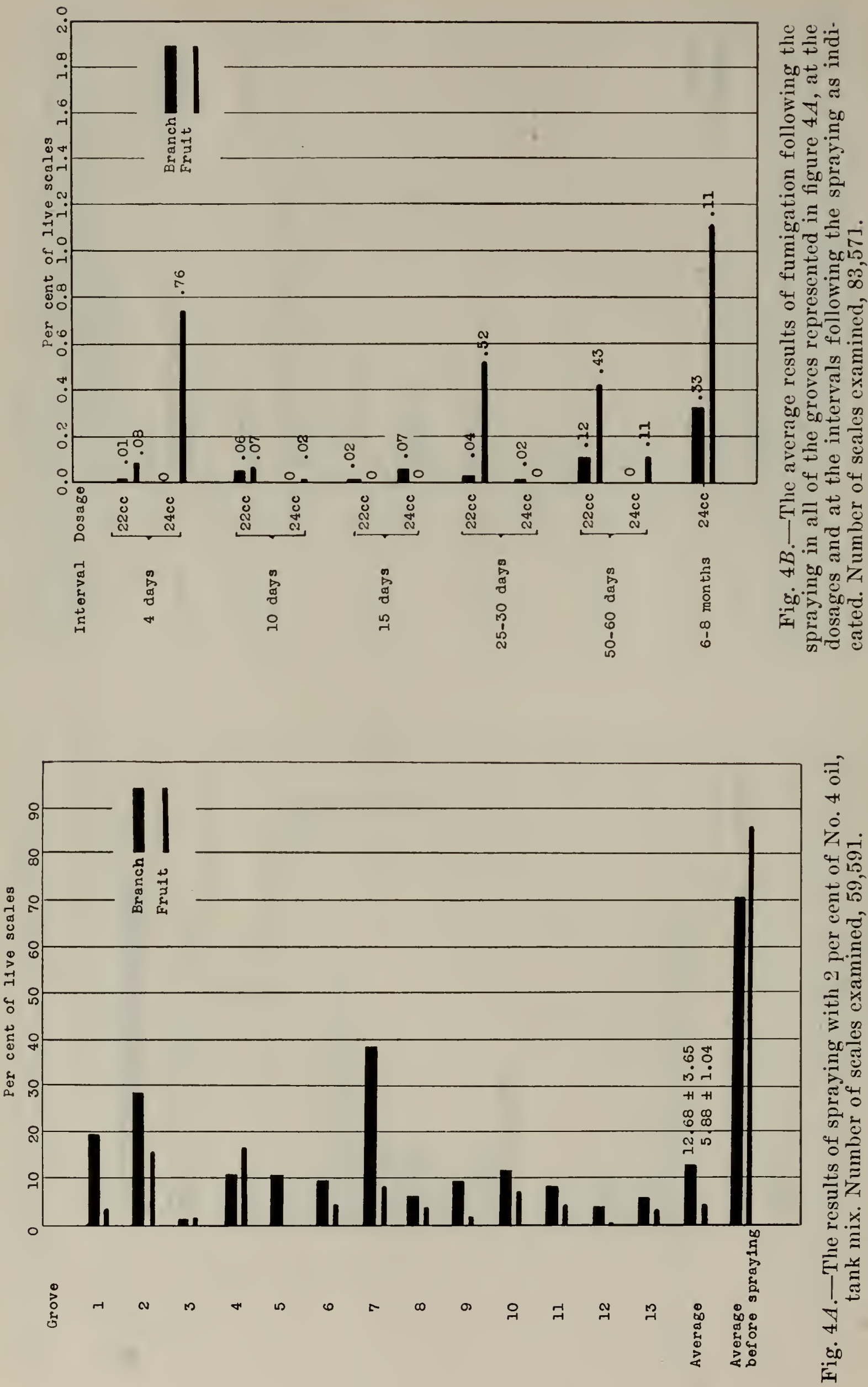

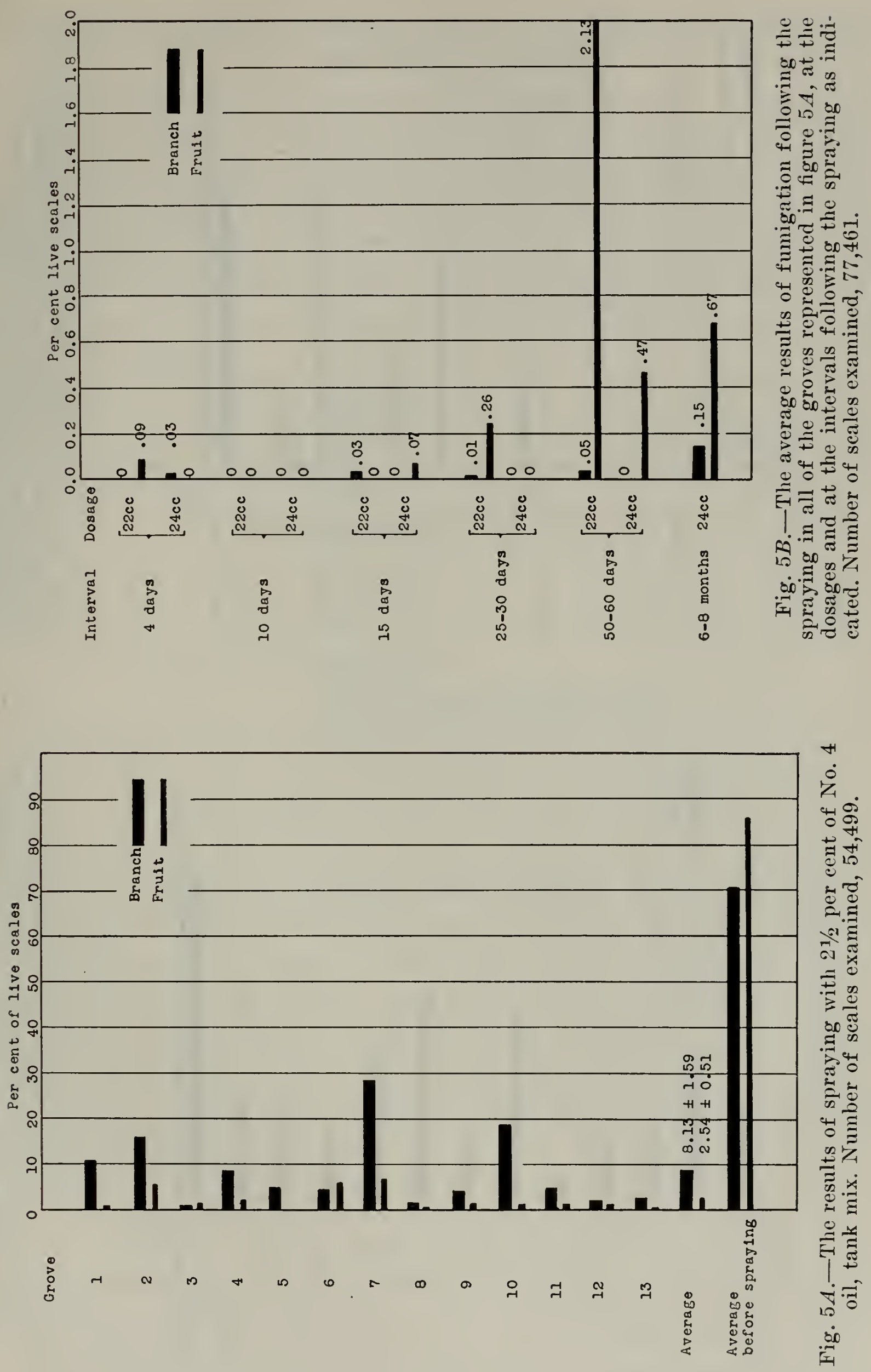

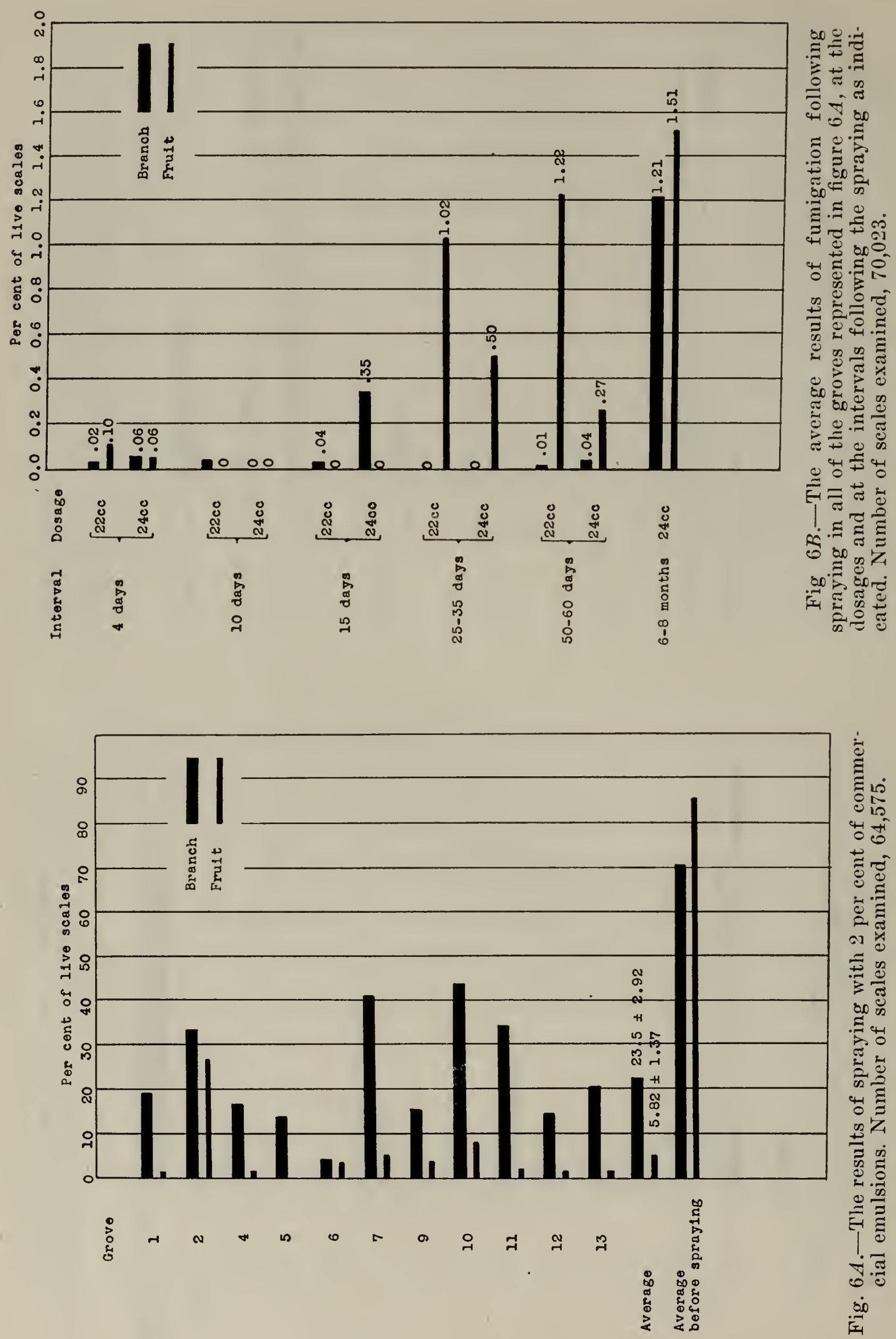


\section{EFFECT OF SPRAY-FUMIGATION TREATMENT ON INSECTS NOT HIT BY SPRAY}

Experiments were conducted to determine if the results of fumigation were more effective on those scales not covered by the spray on sprayed trees than on scales on trees that had not been previously sprayed. It is scarcely possible to spray a citrus tree so as to effect a complete coverage, yet the results sometimes secured by the spray-fumigation treatment were so satisfactory that it was thought that the fumigation after

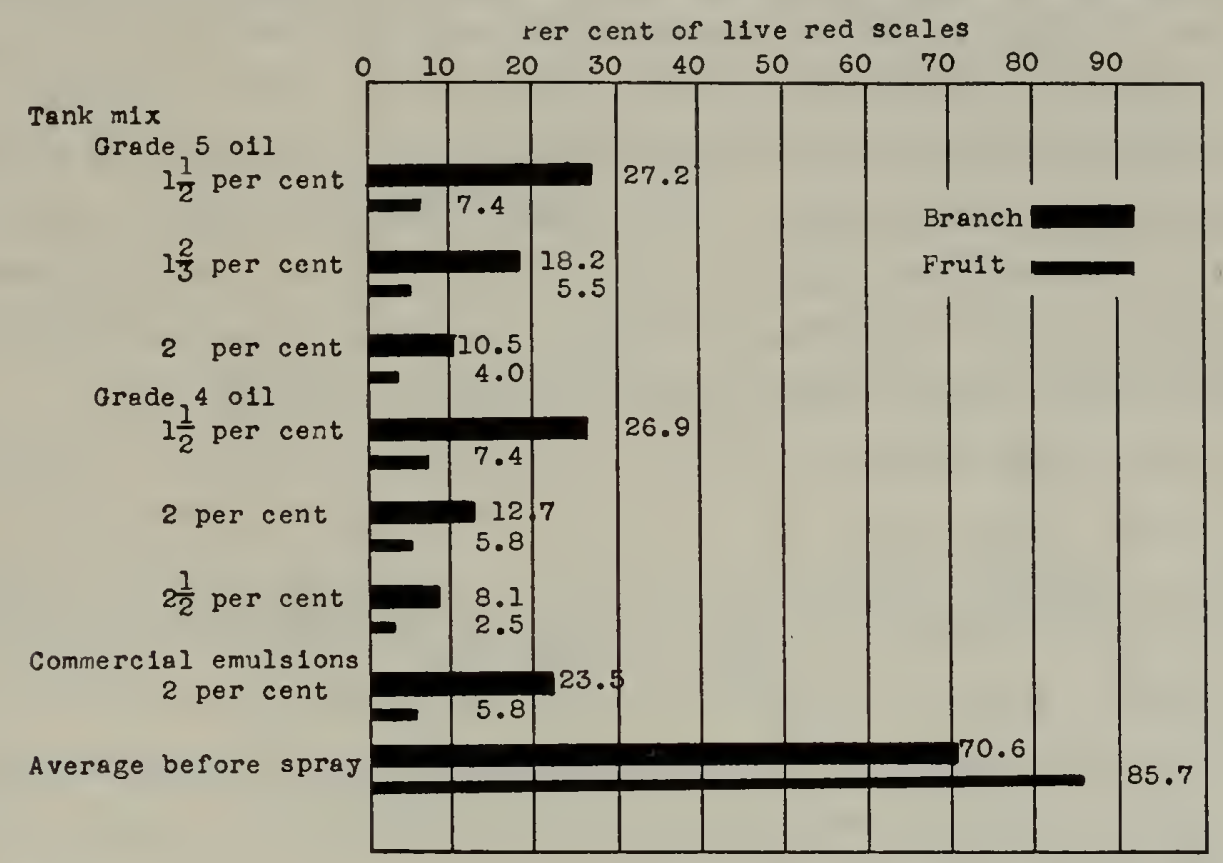

Fig. 7.-A comparison of the results of all of the oil sprays used in all of the groves. Number of scales examined, 404,772 .

spraying must effect a higher kill than when used alone, even on scales not hit by the spray. Red-scale-infested lemons were sprayed in such a way that one half of each fruit was covered with the spray, while the other half was not. Some of these fruits were then fumigated. On one set of checks, spray alone was used and on another fumigation alone.

The results indicated that the spray did not increase the effectiveness of the fumigation except when the spray actually covered the insects. The spray applied to one half of the fruit did not affect the fumigation results on the other half. For the best results, therefore, a thorough spray coverage is necessary.

\section{LIFTING OF SCALE COVERING BY OIL SPRAY}

The question of the scale covering's being lifted or loosened from the surface on which it is resting, and thus accounting for an increased kill by fumigation, has been given some attention. While the lifting of the scale covering is one of the effects often observed after the application of 
oil sprays, the extent to which it occurs varies greatly under different conditions. In one instance, an actual count of 5,000 scales examined the next day after applying an oil spray (Grade 5 , at 2 per cent) showed that the scale covering of 15 per cent of the scales had been lifted (that is, a portion of the margin of the covering was appreciably detached from the surface of the fruit), and that of 18 per cent by the second day.

To determine if the scales with their coverings lifted were more susceptible to $\mathrm{HCN}$, a large number of scale coverings were artificially lifted on a portion or entirely around the margin, while others on the same or separate fruits were left undisturbed. The artificial lifting of the scale coverings caused in itself little or no mortality of the scales, as determined by the checks. The scales with the lifted and unlifted coverings were then fumigated in the same chamber. The percentage of survival of the scales with the unlifted coverings was about 50 per cent higher than that of the scales with the lifted coverings.

From such experiments and from field observations, it is concluded that the spray causes some of the insects to be more susceptible to the fumigation. Another factor, not subject to experimental proof, may be that the shock or reduced vigor of some of the scales which have survived the spray may be sufficient to cause the scales to succumb with the added effect of fumigation. Such direct auxilliary effect of the spray on the fumigation is of course lost when the fumigation is postponed until six to eight months after the spray.

\section{TOLERANCE OF HCN BY THE TREE AFTER SPRAYING}

Oil spray may have another influence on fumigation. Hydrocyanic acid is not absorbed by the oil, consequently there may be less absorption by the tree where the surface is covered with oil; if so, a higher concentration of HCN could be used in the air surrounding the insect, without injury to the tree. Some tests have shown that an oil-sprayed tree is less likely to be injured by fumigation than a tree under the same conditions which has not been sprayed (Quayle, 1922). Other comparative tests have shown that there is little or no increased protection from oil spray coverage. A number of different factors may influence fumigation injury, such as type of oil, interval between spraying and fumigation, condition of the tree, season and weather. The oil that will remain longest on the surface has the greatest influence and to get the full effect of the protective action the fumigation should soon follow the spraying.

In order to determine the protective action, if any, of the oil, 96 rooted cuttings of lemon were divided into lots of four. One cutting from 
each lot was sprayed with $12 / 3$ per cent of Grade 5 oil. These lots were then fumigated from one to two weeks after the spray had been applied. The three remaining cuttings from each lot were fumigated at the same dosage without previous spraying.

Out of the 96 plants representing the 24 fumigations of 4 plants each, 50 per cent of the plants which had been previously sprayed were injured, and 50 per cent of those that had not been sprayed were injured. According to this test, therefore, the effect of previous oil spraying on the particular plants and under the particular conditions had no effect on the injury that occurred from fumigation. While there is conflicting evidence in the field, previous oil spraying tends to show a decrease rather than an increase in the injury to the tree when fumigated later.

Since August or early September is the preferable period for applying the spray, from the standpoint of tree tolerance, and since fumigation may be postponed to a much later date, the preferable sequence is to apply the spray first, even though spraying may not decrease fumigation injury.

\section{EFFECT OF SPRAY-FUMIGATION ON RED-SCALE POPULATION}

The groves represented in the charts (figures 1 to 6 ) were selected because of the heavy infestation of red scale. The spray-fumigation treatment was therefore given a rather severe test. Considering the heavy initial infestation, the results secured were satisfactory. In less heavily infested groves, which would better represent average conditions, the results would be even more satisfactory. Any treatment for the red scale, however, must give a high degree of control because of the rapid increase of the scale within a single season. The extent of increase of the scale in different years depends greatly upon winter conditions. For example, during the unusually mild winter of 1933-34, emergence of young red scale continued without interruption. During cold, wet winters there may be practically no emergence of young for three or four months.

A study was made in the fall and winter of 1931-32 of the decline in the red-scale population on 10 trees in each of 16 groves following the spray treatment in September, 1931, and fumigations in September, 1931, and March, 1932. Counts were made of the number of insects per unit area on the branches of the trees before the spray treatment, six weeks after the spray treatment, and in the spring after the spring fumigations. Counts were also made in the spring on the trees sprayed the previous fall but not fumigated. The method of counting was to select four main branches on each of ten trees in each grove and count the 
number of live insects on these branches from the trunk to the terminal twig. The counts were made only on plots sprayed with 2 per cent heavy oil, Grade 5. The results are presented in table 2.

TABLE 2

Reduction in the Number of Live Insects Per Unit Area During the WINTER AND SPRING OF 1931-32

\begin{tabular}{|c|c|c|c|c|c|c|}
\hline \multirow[b]{2}{*}{ Grove No. } & \multicolumn{3}{|c|}{ Sprayed only } & \multicolumn{3}{|c|}{ Spray-fumigation } \\
\hline & $\begin{array}{c}\text { Insects alive } \\
\text { before spraying }\end{array}$ & $\begin{array}{l}\text { Insects } \\
\text { alive after } \\
\text { spraying in } \\
\text { September }\end{array}$ & $\begin{array}{c}\text { Insects } \\
\text { alive in spring } \\
\text { in sprayed } \\
\text { plots }\end{array}$ & $\begin{array}{l}\text { Insects } \\
\text { alive } \\
\text { in spring } \\
\text { in fall- } \\
\text { fumigated } \\
\text { plots }\end{array}$ & $\begin{array}{c}\text { Insects } \\
\text { alive } \\
\text { in spring } \\
\text { in spring- } \\
\text { fumigated } \\
\text { plots }\end{array}$ & $\begin{array}{l}\text { Gas used in } \\
\text { spring }\end{array}$ \\
\hline 1 & 1,298 & 319 & 59.2 & 4.0 & 1.6 & Cold \\
\hline 2 & 306 & 29 & 7.5 & 0.9 & 2.8 & Cold \\
\hline 3 & 2,100 & 168 & 11.7 & 0.9 & 1.1 & Cold \\
\hline 4 & 471 & 57 & 8.7 & 1.2 & 2.0 & Cold \\
\hline 5 & 4,718 & 875 & 28.4 & 0.8 & 0.1 & Hot \\
\hline 6 & 2,216 & 196 & 4.9 & 0.7 & 0.0 & Hot \\
\hline 7 & 4,061 & 406 & 2.5 & 0.3 & & \\
\hline 8 & 2,481 & 380 & 12.0 & 0.5 & 0.0 & Cold \\
\hline 9 & 4,798 & 336 & 31.5 & 0.2 & 0.1 & Hot \\
\hline 10 & 1,612 & 129 & 4.6 & & & \\
\hline 11 & 2,527 & 178 & 2.9 & ....... & ....... & \\
\hline 12 & 3,243 & 359 & 3.7 & ....... & 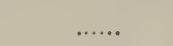 & \\
\hline 13 & 4,352 & 246 & 17.9 & 3.3 & 7.7 & Cold \\
\hline 14 & ............ & $\ldots \ldots$. & ......... & 0.0 & 0.1 & Cold \\
\hline 15 & ............ & ....... & $\ldots \ldots \ldots$ & 0.0 & 0.2 & Cold \\
\hline 16 & $\ldots \ldots \ldots \ldots$ & ....... & & 0.2 & 1.7 & Cold \\
\hline
\end{tabular}

\section{2-33 SPRAY-FUMIGATION EXPERIMENTS}

It has already been mentioned that the results of the spray-fumigation experiments were satisfactory. It was deemed advisable to secure additional information on the efficacy of this method of treatment by repeating the tests in eight of the groves included in the 1931-32 experiments. The plots sprayed with Grade 4 oil at $21 / 2$ per cent were again sprayed with this concentration of Grade 4 oil the following fall (August, 1932) and fumigated ten days later with a 22-cc schedule.

The following April counts were made of the number of insects surviving per unit area of the tree (table 3). The terminal 12 inches of 20 green twigs and 20 mature fruits on every tree in the plot were examined for red scale. The counts indicate a very high degree of commercial control effected in the course of two years in the resistant-red-scale areas of Orange County on trees which in the fall of 1931 were the most heavily infested of any that could be found in that area. 


\section{SPRAY-FUMIGATION COMPARED WITH TWO FUMIGATIONS}

A comparison of spraying and fumigation with two fumigations was made in a lemon grove in a resistant-red-scale district of Orange County, in September, 1932. A block of 40 trees was employed in this experiment. Ten trees were sprayed with Grade 5 oil at 2 per cent concentration; ten were sprayed with the same concentration and fumigated ten days later;

\section{TABLE 3}

Number of Red Scales Alive Per Tree in Plots Having Spray-Fumigation Treatment For Two Years (1931 and 1932); Twenty Green Twigs and Twenty Mature Fruits Examined on Each Tree

\begin{tabular}{|c|c|c|c|}
\hline \multirow{2}{*}{ Grove No. } & \multirow{2}{*}{$\begin{array}{l}\text { Number } \\
\text { of trees } \\
\text { examined }\end{array}$} & \multicolumn{2}{|c|}{$\begin{array}{l}\text { Average number of insects } \\
\text { alive per tree }\end{array}$} \\
\hline & & On twigs & On fruit \\
\hline $1 \ldots \ldots \ldots$ & 12 & 0.66 & 0.00 \\
\hline $2 \ldots$ & 6 & 2.83 & .50 \\
\hline $3 \ldots$ & 6 & 0.33 & .00 \\
\hline $4 \ldots$ & 10 & 1.40 & .20 \\
\hline $5 \ldots$ & 12 & 0.50 & .83 \\
\hline ...……... & 6 & 0.66 & .33 \\
\hline $7 \ldots$ & 6 & 9.83 & .16 \\
\hline $8 \ldots$ & 10 & 3.16 & 0.16 \\
\hline
\end{tabular}

ten were fumigated once; and the remaining ten twice, leaving a 30-day interval between the fumigations. A 22-ce schedule was used in all fumigations. Six months after the last fumigation, counts were made of the number of live insects on four main branches from the trunk to the tip of the branch on each tree. The results of the counts are as follows :

Treatment
Spray.... fumigation
Spray + fumigation....
Two fumigations.
spite of the fact that fumigation is most effective on the branches,
live insects
per tree



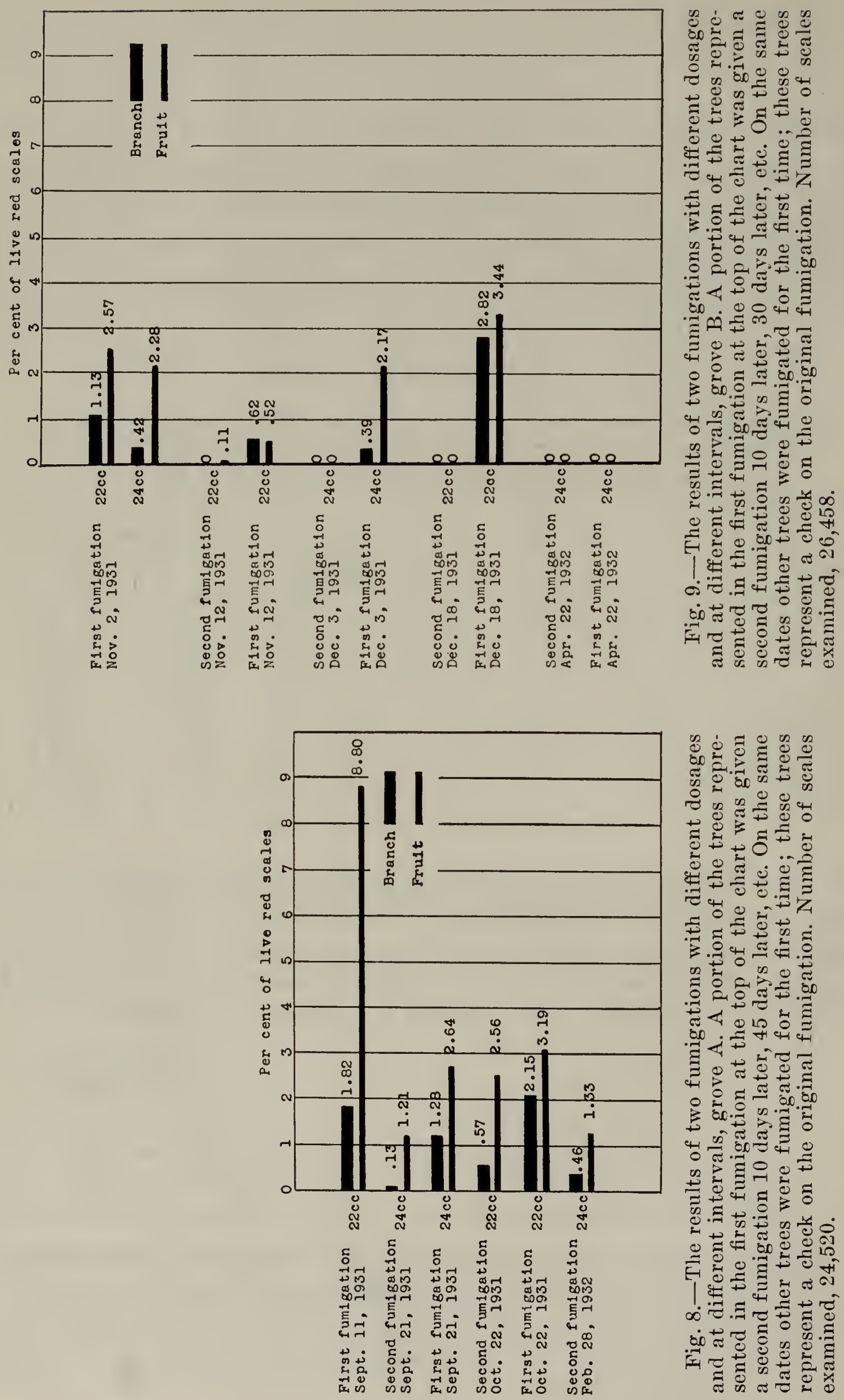


\section{EXPERIMENTS WITH TWO FUMIGATIONS}

In order to make a further study of the value of two fumigations, two groves were selected for this experiment. Where a double fumigation is employed against the red scale, the most important factor is the interval between the treatments. Since the red scale is most difficult to kill when it is in the second molt, the development of the scale should be taken into consideration in deciding upon the interval. The second molt may occur in as short a time as twenty days after settling during the warmest weather in the warmest sections, or it may be extended to from forty to fifty or sixty days. The time the insect is in the molting stage varies from two or three days to a week or more, according to the temperature. The shortest interval, therefore, between two fumigations should be about two weeks, while under average summer conditions in most sections the interval might be extended to three or four weeks.

The results of the two fumigations in grove $A$, as given in figure 8 , are not as satisfactory as that of the best spray-fumigation treatments. In grove $B$, figure 9 , however, the two fumigations gave a very high degree of control. The results as given in these two groves are not based on sufficient data to be reliable. The effect of the different intervals was of chief interest, but the scale infestation was scarcely severe enough to furnish an adequate comparison.

From tests carried on in previous years, and from observations of commercial work, two fumigations have not quite equaled a spray-fumigation treatment where the red scale is known to be resistant to fumigation. This is due primarily to the fact that the scales on the fruit, particularly the fruit on the outside of the tree, are most likely to survive the second as well as the first fumigation. If all stages of the scale except the most resistant stage, or second molt, may be killed by the first fumigation, then a second fumigation properly timed will result in a high degree of control. Where the scale is particularly resistant, however, other stages than the second molt escape the fumigation, and it is not possible to time the two fumigations so as to get all of the scales in susceptible stages.

\section{DISCUSSION}

The actual percentage of insecticidal efficiency of the spray-fumigation or two fumigations compares favorably with any treatment within the field of economic entomology. Many apple growers throughout the country spray from four to eleven times a year and still have 30 to 40 per cent of wormy apples. California lemon growers are confronted with a much less serious situation with the red scale, particularly on the direct 
effect on the crop, but at the same time the writers fully appreciate the importance of the problem. Aside from the cost, the chief objection to the spray-fumigation treatment is that in the interior sections, as compared with the coastal sections, the lemon is more adversely affected by the heavy type of oil that is necessary for the best results on the insects.

Where the scale population is not too high to start with, the sprayfumigation treatment controls the red scale satisfactorily. Where the population is high, treatments repeated at frequent intervals are necessary to reduce the population to a point where the actual numbers of scales surviving will be too small to allow of a very serious build-up within a single season. During the 1931-32 and 1932-33 seasons, which were not far from normal, the winter conditions were such as to check the increase for a few months, with the result that the red-scale situation was greatly improved. During the 1933-34 season, uninterrupted development occurred throughout the winter. Furthermore, the results of the two previous years induced many growers to spray in the fall and omit the fumigation later, with the result that the red scale has again greatly increased. Had the spray-fumigation treatment been persistently carried out each year, many groves would have come through the abnormal season of 1933-34 in a much better condition.

\section{SUMMARY}

Thirteen lemon groves in Los Angeles and Orange counties, selected because of the heavy infestation of the red scale, were involved in the experiments reported herein.

There were six different plots of from 25 to 30 trees in each grove. Six different spray treatments were applied, each of which was followed by fumigation of two different dosages at intervals of from four days to eight months.

The insect mortality was determined in all cases before treatment, and extensive counts made as to the results following the treatment.

The average results of all of the different sprays in all of the groves ranged from 72.8 to 91.9 per cent of the scales killed on the branches, and from 91.6 to 97.5 per cent of the scales killed on the fruit.

The range in spray-fumigation results in the different groves and at all intervals and dosages was from 99.63 to 100 per cent of the scales killed on the branches, and from 98.86 to 100 per cent of the scales killed on the fruit.

The range in results in the two groves where fumigation alone was employed was, for a single fumigation, from 97.18 to 100 per cent of the scales killed on the branches, and from 91.0 to 100 per cent on the fruit. 
The results of two fumigations ranged from 99.42 per cent to 100 per cent of the scales killed on the branches, and from 97.35 to 100 per cent on the fruit.

The figures given for the spray-fumigation treatment, and also for the two fumigations, represent high insecticidal efficiency.

A high percentage of efficiency may be misleading to the grower whose criterion of effective treatment is a reasonably clean grove for at least one year. If there is a high population of the red scale to start with, 99 per cent control is scarcely sufficient. If 99 per cent control can be obtained, however, even severe infestations can be reduced by repeated treatments. Once the population is low, satisfactory control can be maintained. In much of the citrus area spraying is necessary anyway for the red spider; hence the cost of the spray-fumigation treatment should not be chargeable to the red scale alone, since it practically completes the annual pest-control program for lemons. 


\section{LITERATURE CITED}

Ebeling, WALter.

1931. Method for the determination of the efficiency of sprays and HCN gas used in the control of the red scale. California Dept. Agr. Mo. Bul. 20:669-671.

1932. Experiments with oil sprays used in the control of the California red scale, Chrysomphalus aurantii (Mask.). Jour. Econ. Ent. 25:1007-1012.

Gray, Geo. P., AND A. F. Kirkpatrick.

1929. Resistant seale investigations. California Citrograph 14:208-209.

QUAYLE, H. J.

1916. Are scale insects becoming resistant to hydrocyanic acid fumigation? California Jour. Agr. 3:333-334, 358.

1920. Recent fumigation developments. California Citrograph 5:188-189.

1922. Resistance of certain scale insects in certain localities to hydrocyanic fumigation. Jour. Econ. Ent. 15:400-404.

1927. Spray and fumigation combination for resistant red seale. Jour. Econ. Ent. $20: 667-673$.

Smith, Ralph H.

1932. The tank-mixture method of using oil spray. California Agr. Exp. Sta. Bul. $527: 1-84$.

WOGLUM, R. S.

1925. Observations on insects developing immunity to insecticides. Jour. Econ. Ent. 18:593-597. 